\title{
Eralnterim Re-analiz Verileri Kullanılarak İstatistiksel Ölçek İndirgeme Yöntemi ile Doğu Karadeniz Havzası Aylık Ortalama Sıcaklık Değerlerinin Tahmin Edilmesi
}

\author{
Sinan Nacar ${ }^{1 *} \oplus$, Murat Kankal ${ }^{2} @$, Umut Okkan ${ }^{3}$ \\ ${ }^{1}$ Karadeniz Teknik Üniversitesi, Mühendislik Fakültesi, İnşaat Mühendisliği Bölümü, 61080, Trabzon. \\ 2Uludağ Universitesi, Mühendislik Fakültesi, Inşaat Mühendisliği Bölümü, 16120, Bursa. \\ ${ }^{3}$ Balıkesir Üniversitesi, Mühendislik Fakültesi, Înşaat Mühendisliği Bölümü, 10145, Balıkesir.
}

\section{Özet}

İstatistiksel ölçek indirgeme yöntemleri düşük çözünürlüğe sahip atmosferik değişkenler ile istasyonlardan ölçülmüs meteorolojik parametreler arasında istatistiksel ilişkiler kurulmasına dayanan yöntemlerdir. Bu çalışmada $\left(0,75^{\circ} x \quad 0,75^{\circ}\right)$ saylsal ă̆ çözünürlü̈̆̈̈ne sahip EraInterim re-analiz veri setinde yer alan atmosferik değişkenler kullanılarak Doğu Karadeniz Havzası'nda ve çevresinde yer alan 12 meteoroloji istasyonundan ölçülmüş olan aylık ortalama slcaklık parametresinin her bir istasyon için tahmin edilmesi amaçlanmıștır. Bu amaçla EraInterim re-analiz veri setinde yer alan yüzeysel parametrelerden yağıs, sıcaklık, deniz yüzeyi basıncl ve yüzeysel hava basıncı ile 850, 500 ve $200 \mathrm{hPa}$ basınç seviyelerindeki hava sicaklığl, jeopotansiyel yükseklik ve rölatif nem atmosferik değișkenleri bağımsız değișkenler olarak kullanılmıștır. Meteoroloji istasyonlarından (1981-2010) döneminde ölçülmüs olan aylık ortalama sıcaklık değerleri ise bağımlı değişken olarak kullanılmıştır. Ölçek indirgeme yöntemi olarak çok değişkenli uyarlanabilir regresyon eğrileri (ÇDURE) yöntemi seçilmiştir. İstasyon temelinde kurulmuş olan ÇDURE model performanslarının değerlendirilmesi için ortalama karesel hatanın karekökü, saçılım indeksi, ortalama mutlak hata ve Nash-Sutcliffe (NS) etkinlik katsayısı istatistikleri kullanılmıştır. Hesaplanan NS değerinin tüm istasyonlar için 0.9-1.0 aralı̆̆ında olduğu görü̈lmüştür. Ayrıca EraInterim veri setinden seçilmis olan küresel ölçekli değișkenlerin yerel ölçekteki sicaklık değerleri tahmininde başarılı olduğu ortaya çıkmıştır. Bu sonuçlar ÇDURE istatistiksel ölçek indirgeme yönteminin kaba ölçekli atmosferik değişkenlerin bölgesel ölçeğe indirgenmesinde kullanılabilir olduğunu göstermiştir.

Anahtar Sözcükler

EraInterim, ÇDURE, Doğu Karadeniz Havzası, İklim Değişikliği, İstatistiksel Ölçek İndirgeme, Sıcaklık

\section{Estimation of the Monthly Mean Temperature Values of the Eastern Black Sea Basin with Statistical Downscaling Method Using Eralnterim Re-analysis Data}

\begin{abstract}
Statistical downscaling methods are based on determination of statistical relationships between low resolution atmospheric variables and measured climate parameters from meteorological stations. In this study, it was aimed to estimate the monthly mean temperature measured from 12 meteorological stations in and around the Eastern Black Sea Basin using atmospheric variables in the EraInterim re-analysis data set with grid resolution $\left(0.75^{\circ} \times 0.75^{\circ}\right)$. For this purpose, the variables of precipitation, temperature, sea surface pressure, surface air pressure and air temperature, geopotential height and relative humidity at 850, 500 and $200 \mathrm{hPa}$ pressure levels in the EraInterim re-analysis data set were used as independent variables. Monthly mean temperature values measured from meteorological stations (1981-2010) were used as dependent variables. Multivariate adaptive regression splines (MARS) method selected as downscaling method. The root mean square error, scattering index, mean absolute error and Nash Sutcliffe (NS) efficiency coefficient statistics were used to evaluate the performance of the MARS model based on the station. The NS value calculated for all stations was in the range of 0.9-1.0. In addition, the global scale variables selected from the EraInterim data set were found to be quite successful in estimating local temperature values. The results obtained from the study showed that MARS statistical downscaling method can be used to downscale the coarse scale atmospheric variables to the regional scale.
\end{abstract}

Keywords

EraInterim, MARS, Eastern Black Sea Basin, Climate Change, Statistical Downscaling, Temperature

\footnotetext{
* Sorumlu Yazar: Tel: +90 (462) 3772606 Faks: +90 (462) 3774413

E-posta: sinannacar@ktu.edu.tr (Nacar S), mkankal@uludag.edu.tr (Kankal M), umutokkan@balikesir.edu.tr (Okkan U)
}

Gönderim Tarihi / Received : 06/03/2020

Kabul Tarihi / Accepted

: 25/05/2020 


\section{Giriş}

Küresel ısınma ve buna bağlı olarak meydana gelen iklim değişikliği, etkileri ve sonuçları açısından dünyanın bütün ülkelerini yakından ilgilendiren önemli bir sorun niteliğindedir (Bayraç ve Doğan 2016). Bu sebeple iklim değişikliği etkisiyle meydana gelecek problemlerin ortaya konması ve iklim değişikliği etkilerine karşı gerekli tedbirlerin belirlenmesi bilim dünyasının son yıllarda üzerinde çalıştığı en güncel konular arsında yerini almıştır. İklim değişikliği etkilerine karşı alınacak tedbirlerin siyasi, politik ve çevresel yönlerinin olması iklim değişikliği konusunun Birleşmiş Milletler öncülüğünde dünya gündemine taşınmasını sağlamıştır. Küresel ısınma sonucu meydana gelen iklim değişikliği etkilerini belirlemek, bu konuda yapılmış olan çalışmaları değerlendirerek hükümetlere iklim değişikliği hakkında raporlar hazırlamak amacıyla Birleşmiş Milletlerin iki örgütü olan Dünya Meteoroloji Örgütü ve Birleşmiş Milletler Çevre Programı aracılığıyla 1988 yılında Hükümetler Arası İklim Değişikliği Paneli (IPCC) kurulmuştur (MGM 2015). IPCC kurulduğu tarihten itibaren birçok panel gerçekleştirmişstir. Bu panellerden birincisi 1990 (FAR), ikincisi 1996 (SAR), üçüncüsü 2001 (TAR), dördüncüsü 2007 (AR4) beşincisi 2013 (AR5) y1lında yapılmıştır. Bunların dışında hükümetlere iklim değişikliği hakkında güncel bilgileri aktarabilmek amacıyla farklı tarihlerde toplantılar düzenlenmiştir. IPCC'nin AR5'te, mevcut küresel ortalama yüzey sıcaklığının 1880'den 2012'ye kadar 0.85 $\mathrm{C}^{\circ}$ arttığı ve 21. Yüzyıl ilk dönemindeki yılların ortalama sıcaklıklarının bugüne kadar ölçülmüş en sıcak yıllar olarak kayda geçtiği ifade edilmiştir (IPCC 2013). Daha sonra 6.000'in üzerinde bilimsel çalışma incelenerek hazırlanan IPCC

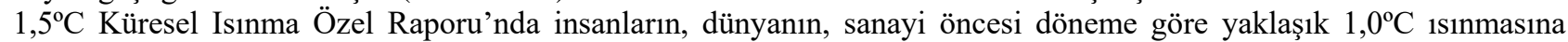
sebep olduğu ifade edilmiştir. İnsan etkisiyle meydana gelen bu küresel 1sınmanın şimdiden, kuraklık ve taşkınlar gibi aşırı hava olaylarına, deniz seviyesinde yükselmeye ve buzulların erimesi gibi aşırı hava olaylarına sebep olduğu ifade edilmektedir (IPCC 2018).

İklim değişikliği etkileriyle meydana gelen aşırı hava olaylarına karşı gereken tedbirlerin alınması, küresel olarak meydana gelen 1sınmanın yerel ölçekteki etkilerinin belirlenmesi ile mümkündür. Yerel ölçekte meydana gelecek iklim değişikliği etkilerini ortaya koymak için ise iklim parametrelerinin önceden belirlenmesi gerekmektedir. Gelecek dönemlerde yaşanabilecek iklimin önceden belirlenmesine yönelik en kapsamlı çalışmalar iklim modelleme çalışmaları olarak görülmektedir (Demir vd. 2013; Demircan vd. 2014). Bu kapsamda en çok kullanılan yaklaşım ise genel dolaşım modelleri (GDM) çıktılarının kullanılması yaklaşımıdır. GDM çıktıları kullanılarak üretilen senaryo verileri diğer yaklaşımlara göre çok daha güvenilir olduğundan iklim bilimciler tarafından tercih sebebi olmuştur (Wilby ve Harris 2006). Ancak GDM veri takımlarının çözünürlüklerinin çok düşük olması sebebi ile bu veriler kullanılarak yerel ölçek için tahminde bulunmak mümkün değildir. Bu sebeple GDM'lerin büyük ölçekli hazırlanmış olan tahminlerinin bölgesel ölçeğe indirgenmesi gerekmektedir. Bu kapsamda dinamik ve istatistiksel ölçek indirgeme yöntemleri olarak adlandırılmış iki temel ölçek indirgeme yöntemi geliştirilmiştir (Tripathi vd. 2006). Bu yöntemlerden dinamik ölçek indirgeme yöntemi fiziksel iklim modellerine dayalı çalışmaları kapsamaktadır. Bu modeller, başlangıç ve sınır koşullarını küresel ölçekli model çıktılarından almakta ve topografya özelliklerinin de hesaba katılmasıyla daha yüksek çözünürlüklerde çalıştırılabilmektedir. Böylece orografik yağışlar, aşırı hava olayları ve bölgesel ölçekteki iklimsel anomaliler, bölgesel iklim modelleri ile dikkate alınabilmektedir (Crane ve Hewitson 1998; Mearns vd. 1999; Frei vd. 2003; Fowler vd. 2005; Okkan ve Karakan 2016). Bu yöntemde başlangıç koşulları, ölçeği indirgenecek olan küresel dolaşım modelinden alınmaktadır. Dinamik ölçek indirgeme yöntemlerinde küresel modellere benzer fiziksel ve kimyasal süreçler yer almaktadır (Atay 2015). Dinamik ölçek indirgeme yönteminden elde edilen sonuçlar bir anlamda GDM ve yerel özelliklerin birlikte belirlediği yerel tahminler olarak nitelendirilebilir. Buradaki en büyük zorluk ise, alan küçülmesine rağmen çözünürlüğün artması ve yerel şartların hesaplamalara dâhil olması nedeniyle önemli bir bilgisayar kapasitesine ihtiyaç duyulmasıdır (MGM 2015; Nacar vd. 2019). İstatistiksel ölçek indirgeme yöntemleri ise kaba çözünürlüklü atmosferik değişkenler ile gözlem verileri arasında bir takım bağıntılar kurma temeline dayanan yöntemlerdir. Çok değişkenli doğrusal-doğrusal olmayan regresyon tipleri, yapay sinir ağları (YSA) algoritmaları, destek vektör makinaları, asal bileşen analizi, kanonik korelasyon analizi gibi birçok yöntem bu kapsamda ele alınmaktadır (Fistikoglu ve Okkan 2010; Okkan ve Fistıkoğlu 2014). İstatistiksel ölçek indirgeme yöntemleri kullanım, uygulama ve performanslarını test etme kolaylığı, ihtiyaç duyulan bilgisayar gücü kapasitesinin ve modellemede kullanılan değişken sayısının az olması avantajları sebebiyle iklim değişikliği etkilerini inceleyen araştırmacılar tarafindan sıklıkla kullanılmaktadır (Chen vd. 2012; Wagesho vd. 2012; Okkan ve Karakan 2016; Hamlet vd. 2019; Akhter vd. 2019).

Kaba çözünürlüklü tahminlere sahip iklim modeli sonuçlarının bölgesel ölçekteki iklim parametrelerine indirgenmesinde kullanılan istatistiksel ölçek indirgeme yönteminin uygulanabilmesi için birçok ülkenin ulusal arşivleri, meteoroloji gözlem istasyonları, gemi ve uçak gözlemleri, uydu verileri ve hava tahmin modelleri kullanılarak farklı kurumlar tarafından üretilen re-analiz verilerinden yararlanıldığı görülmektedir. NCEP/NCAR, Era40, EraInterim ve JRA25 son yıllarda en sık kullanılan re-analiz veri takımlarıdır (Murakami 2014). İstatistiksel ölçek indirgeme çalışmalarında Re-analiz veri takımları arasından EraInterim re-analiz veri seti yüksek çözünürlüklü verilere sahip olması sebebi ile ölçek indirgeme çalışmalarında sıklıkla kullanılmaktadır (Vu vd. 2016; Okkan ve Kirdemir 2016; Horton vd. 2018). 
Doğu Karadeniz Havza’sı Türkiye’nin kuzey kıyılarında yer alan ve yıl boyu yağış alan önemli hidrolojik havzalardan biridir. Hidrolojik döngüyü etkileyen en önemli parametrelerden biri olan sıcaklık parametresinin, küresel verileri kullanarak modellenebilmesi, gelecek dönem GDM senaryo verilerinde yer alan sıcaklık verilerinin bölgesel ölçeğe indirgenmesinde büyük öneme sahiptir. Bu çalışmanın amacı $\left(0,75^{\circ} \times 0,75^{\circ}\right)$ çözünürlüğe sahip EraInterim re-analiz veri seti içerisinde yer alan 12 adet atmosferik değişkeni kullanarak ÇDURE istatistiksel ölçek indirgeme yöntemi ile Doğu Karadeniz Havzası ve çevresinde yer alan 12 istasyondan ölçülmüş olan aylık ortalama sıcaklık değerlerini tahmin etmektir. Yapılmış çalışmalar incelendiğinde Doğu Karadeniz Havzası için re-analiz verileri kullanılarak yapılmış bir istatistiksel ölçek indirgeme çalışmasına rastlanmamıştır. Bu çalışma bu alanda yapılmış olan ilk çalışma olacaktır. Bu çalışmadan elde edilen sonuçların, iklim değişikliği etkilerinin belirlenmesine yönelik GDM verileri kullanılarak gelecek dönem iklim verilerinin tahmin edilmesinde araştırmacılara yol göstereceği düşünülmektedir.

\section{Kullanılan Veriler ve Yöntemler}

\subsection{Doğu Karadeniz Havzası}

Türkiye sınırları içerisinde bulunan 26 hidrolojik havzadan biri olan Doğu Karadeniz Havzası, Türkiye'nin kuzey sahil şeridinde yer almaktadır (Şekil 1). Doğuda Kızılırmak Havzası, batıda Çoruh Havzası ve kuzeyde Karadeniz ile çevrelenmiş olan havza, coğrafi bakımdan $40^{\circ} 15^{\prime}-41^{\circ} 34^{\prime}$ kuzey enlemleri ile $36^{\circ} 43^{\prime}-41^{\circ} 35^{\prime}$ doğu boylamları arasinda yer almaktadir.

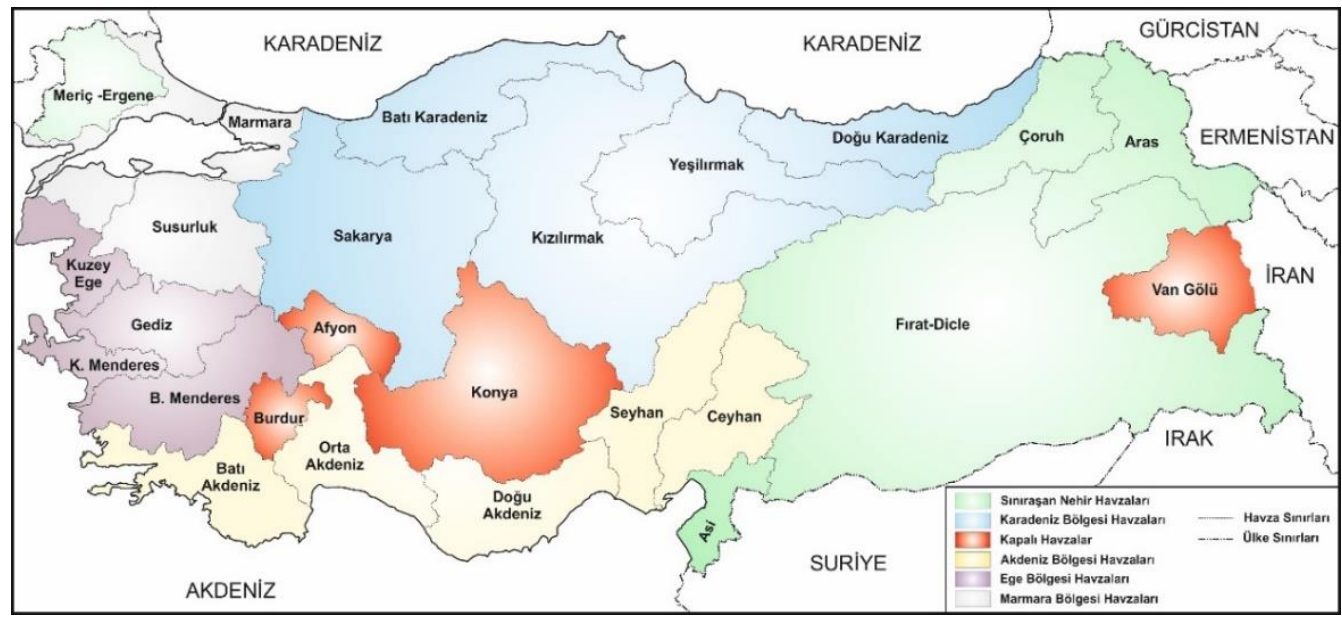

Şekil 1: Türkiye hidrolojik havzaları

Toplam yağış alanı 22.844 km² olan Doğu Karadeniz Havzası'nın yıllık ortalama yağış yüksekliği 1.198 mm; yıllık ortalama akışı ise $566,23 \mathrm{~m}^{3} / \mathrm{s}$ 'dir. Yıllık ortalama verimi $23,57 \mathrm{~L} / \mathrm{s} / \mathrm{km}^{2}$ olan havzadaki akışın yağışa oranı olan akış katsayısı 0,62'dir. Havzada yer alan en önemli akarsu uzunluğu 160 km olan Harşit Çayı'dır. Bunun dışında kaynağını yüksek dağların yamaçlarından alan ve sularını Karadeniz'e boşaltan irili ufaklı pek çok dere vardır (Şekil 2). Bu dereler havzaya düşen bol miktardaki yağışlarla ve yüksek dağ yamaçlarındaki kar sularıyla beslendiklerinden yıl boyu kurumazlar (OSIB 2013; SYGM 2016).

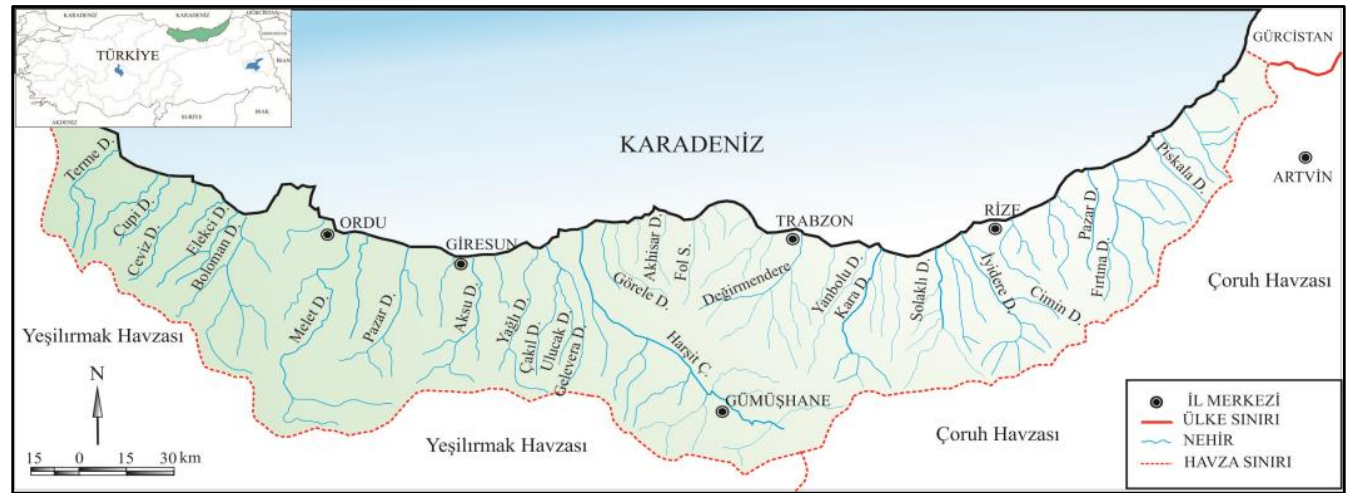

Şekil 2: Doğu Karadeniz havzası akarsuları 
Doğu Karadeniz Havza'sı Türkiye’nin en fazla yağış alan hidrolojik havzasıdır. Yıllık ortalama toplam yağışı 1019 mm'dir. Bu değer Rize ili civarında 2300 mm'lere ulaşmaktadır (Nacar ve Satılmış 2017). Havzanın almış olduğu yağış miktarı ve sahip olduğu engebeli coğrafi yapısı sebebiyle sık sık taşkınlarla gündeme gelmektedir. Doğu Karadeniz Havza'sında 1955-2005 yılları arasında meydana gelen 51 büyük taşkın olayında 258 kişi yaşamını kaybetmiş ve 500 milyon dolarlık ekonomik kayıp yaşanmıştır (Yüksek vd. 2013; Çınakl1 2008). Havzanın yıllık ortalama sıcaklık değeri, 1970-2016 yılları arasında 249 istasyon verisi kullanılarak belirlenen Türkiye yıllık ortalama sıcaklık değeri olan 13,1 ${ }^{\circ} \mathrm{C}$ değerinden yaklaşık $1{ }^{\circ} \mathrm{C}$ fazladır. Doğu Karadeniz Havzası hakkında daha detaylı bilgilere OSİB (2013)'nin hazırlamış olduğu havza koruma eylem planından ulaşılabilir. Çalışma kapsamında Doğu Karadeniz Havzası sınırları içerisinde ve çevresinde yer alan ve bir bölgenin iklimini tayin etmede gerekli olan 30 yıllık (1981-2010) kesintisiz gözlem verisine sahip 12 adet istasyon verisi kullanılmıştır. Bu istasyonların havzadaki konumları Şekil 3'te sayısal yükseklik haritası üzerine işlenerek verilmiştir.

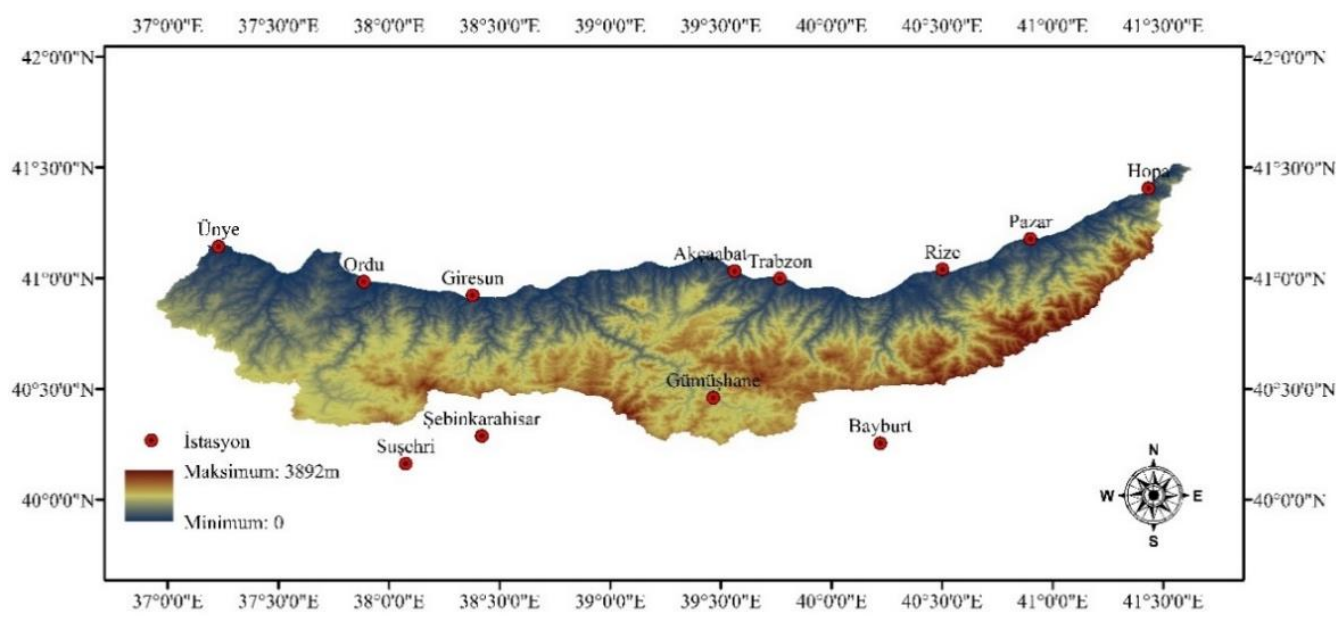

Şekil 3: Çalışma kapsamında verileri kullanılan meteoroloji istasyonları

\subsection{Eralnterim re-analiz veri seti}

EraInterim re-analiz veri seti birçok ülkenin uydu ölçümleri, meteoroloji gözlem istasyonu verileri, radiosonde vb. gibi birçok veri tabanında yer alan verilerin asimilasyonu ile oluşturulmaktadır. Tüm bu gözlem verileri, küresel atmosferik model ile üretilen ürünler ile istatistiki açıdan en uygun yöntemle birleştirilmektedir. Gerçekleştirilen asimilasyon işlemleri sonucunda ise, atmosferin kaotik davranışına çok daha yakın ve tutarlı ürünler elde edilmektedir. EraInterim re-analiz veri seti 1 Ocak 1979 tarihinden günümüze kadar olan dönem için hazırlanmış atmosferik değişkenlere ait verileri içermekte ve sürekli güncellenmektedir. $0,75^{\circ} \mathrm{x} 0,75^{\circ}$ yatay çözünürlüğe sahip olan bu veri seti düşeyde yüzeyden $0,1 \mathrm{hPa}$ basınç seviyesine kadar 60 seviyede veri içermektedir. EraInterim veri seti hakkına daha detaylı bilgilere Berrisford vd. (2009), Berrisford vd. (2011) ve Dee vd. (2011) çalışmalarından ulaşılabilir.

\section{3. Çok değişkenli uyarlanabilir regresyon eğrileri (ÇDURE)}

ÇDURE Friedman (1991) tarafından geliştirilen parametrik olmayan bir regresyon analizi formudur. Bu yöntemin en önemli avantajı, arasında lineer ilişki bulunmayan bağımsız değişkenler ile bağımlı değişken arasındaki karmaşık ilişkiyi basit eşitliklerle açıklayabilmesidir (Kisi ve Parmar 2016). ÇDURE yöntemi bağımlı ve bağımsız değişkenler arasında herhangi bir ilişki varsayımı yapmamaktadır. Bunun yerine regresyon verisinden kendisinin çıkardığı temel fonksiyonlara dayanarak kendisi bir ilişki oluşturmaktadır. Bağımsız değişkenlerin farklı aralıklarına karşılık gelen temel fonksiyonları kullanarak esnek bir regresyon modeli kurar (Toprak 2011). Genel bir ÇDURE modeli (1) numaralı eşitlikteki gibi tanımlanabilir (Özfalcı 2008; Nacar vd. 2018).

$$
Y=\beta_{0}+\sum_{k=1}^{K} a_{k} \beta_{k}\left(X_{t}\right)+\varepsilon_{i}
$$

Burada; k: düğüm sayısını, K: temel fonksiyon sayısını, X: bağımsız değişkeni, $a_{k}$ : k. temel fonksiyonun kat sayısı, $\beta_{0}$ : modeldeki sabit terim, $\beta_{k}\left(x_{t}\right)$ : t. Bağımsız değişken için k. temel fonksiyonu ifade etmektedir. Temel fonksiyon ise aşağıdaki (2) gibi tanımlanır. 
$B_{m}(x)=\prod_{t=1}^{L_{m}}\left[S_{1, m}\left(x_{v(1, m)}-k_{1, m}\right)\right]$

Burada; $\mathrm{L}_{\mathrm{m}}$ : etkileşim derecesini, $\mathrm{S}_{1, \mathrm{~m}}: \in[ \pm 1], \mathrm{k}_{1, \mathrm{~m}}$ : düğüm değerini, $\mathrm{x}_{\mathrm{v}(1, \mathrm{~m})}$ : bağımsız değişken değerini göstermektedir. ÇDURE yönteminde istenen model elde edilene kadar tekrarlanan iki adımlı bir süreç vardır. Bu adımların ilkinde mümkün olan tüm temel fonksiyonlar oluşturulur. Çok büyük bir model bulununcaya kadar yani modelin karmaşıklığı maksimum seviyeye ulaşıncaya kadar eklenen temel fonksiyonlarla model geliştirilir. İkinci adımda oluşturulan maksimum model budanarak, yani önemli bağımsız değişkenler ve bu değişkenlerin karşılıklı etkileşimleri belirlenerek, hata kareler toplamı minimum olan en uygun model oluşturulur (Ünal 2009; Nacar vd. 2018).

\section{Yapılan Çalışmalar}

Çalışma kapsamında ilk olarak Doğu Karadeniz Havzasını temsil eden EraInterim sayısal ağ merkezleri belirlenmiş̧ir. Havzayı temsil ettiği düşünülen EraInterim sayısal ağ merkezleri ve koordinatları Șekil 4'te verilmiștir. Şekil 4'te görüldüğü üzere havzayı temsil eden 14 adet sayısal ağ merkezi $(\mathrm{G})$ belirlenmiştir. EraInterim re-analiz veri setinde yer alan 12 atmosferik değişkene ait NetCDF formatında hazırlanmış olan veriler, havzayı temsil ettiği düşünülen her bir sayısal ağ için ArcGIS yazılımı kullanılarak düzenlenmiştir.

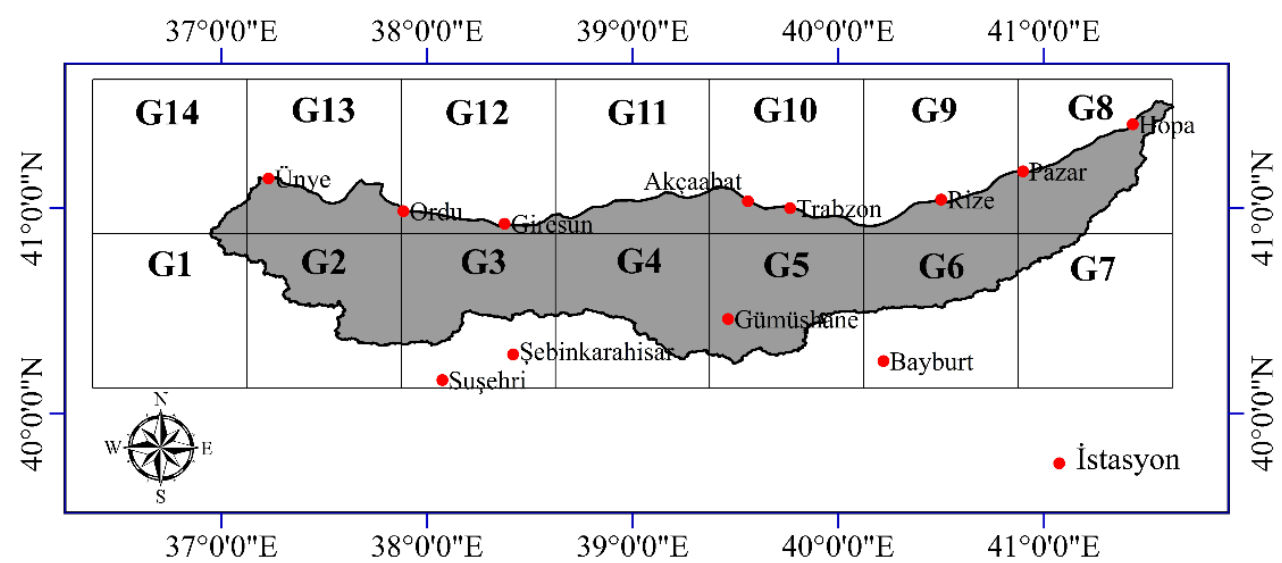

Şekil 4: Doğu Karadeniz Havzasını temsil eden Eralnterim sayısal ağ merkezleri

Çalışma kapsamında kullanılmış olan atmosferik değişkenler Tablo 1'de verilmiştir. Bu atmosferik değişkenler daha önce istatistiksel ölçek indirgeme çalışmalarında kullanılan değişkenler arasından seçilmiştir (Okkan ve Kirdemir 2016; Okkan ve Kirdemir 2018).

Tablo 1: Eralnterim re-analiz veri setinden seçilmiş olan atmosferik değişkenler

\begin{tabular}{ccc|ccc|ccc|cccc}
\hline Basınç Seviyesi & $200 \mathrm{hPa}$ & \multicolumn{3}{|c|}{$500 \mathrm{hPa}$} & \multicolumn{3}{c|}{$850 \mathrm{hPa}$} & \multicolumn{3}{c}{ Yüzey } \\
\hline Atmosferik & air & hgt & air & hgt & rhum & air & hgt & rhum & air & press & slp & prate \\
Değişkenler & $\left({ }^{\circ} \mathrm{C}\right)$ & $(\mathrm{m})$ & $\left({ }^{\circ} \mathrm{C}\right)$ & $(\mathrm{m})$ & $(\%)$ & $\left({ }^{\circ} \mathrm{C}\right)$ & $(\mathrm{m})$ & $(\%)$ & $\left({ }^{\circ} \mathrm{C}\right)$ & $(\mathrm{mb})$ & $(\mathrm{mb})$ & $\left(\mathrm{kg} / \mathrm{m}^{2}\right)$ \\
\hline
\end{tabular}

Tablo 1'de listelenen değişkenler sütununda air: hava sıcaklığını, hgt: jeopotansiyel yüksekliği, rhum: rölatif nemi, press: yüzey basıncını, slp: deniz seviyesi basıncını, prate: yağışı temsil etmektedir. EraInterim veri setinden havzayı temsil eden 14 sayısal ağ merkezi için düzenlenmiş olan atmosferik değişkenlere ait veriler iki gruba ayrılmıştır. Bu sayısal ağlardan havzanın güney bölgesini temsil ettiği düşünülen yedi sayısal ağ verisinin ortalamaları alınarak güneyde yer alan dört istasyonun, havzanın kuzey bölgesini temsil ettiği düşünülen yedi sayısal ağ verisinin ortalamaları alınarak kuzeyde kalan sekiz istasyonun aylık ortalama sıcaklık değerleri tahmininde kullanılmışırı. EraInterim veri takımından alınan atmosferik değişkenler ve her bir istasyondan ölçülmüş olan sıcaklık verileri \%80 eğitim (1981-2004) ve \%20 test (2005-2010) veri takımı olmak üzere ikiye ayrılmıştır. Her bir istasyon için hazırlanan veriler ölçek indirgeme modellerinde kullanılmadan önce standardize edilmiş̧ir. Wilby vd. (2004) yapmış oldukları çalışmalarında standardizasyon işleminin uygulanmasının model sonuçları ile gözlem değerleri arasında meydana gelecek farkları azalttığını ifade etmişlerdir. Standardizasyon işlemi Eşitlik (3) yardımıyla yapılmıştır.

$x_{s}=\frac{x-x_{\text {ort }}}{s_{x}}$ 
$\mathrm{Bu}$ eşitlik yardımıyla ortalaması 0 standart sapması 1 olan bir veri takımı oluşturulmaktadır. Ölçek indirgeme işlemi sonucunda verilere ters standardizasyon işlemi uygulanarak verilerin eski ölçeğine gelmesi sağlanmıştır. İstasyon özelinde ÇDURE tabanlı kurulmuş olan istatistiksel ölçek indirgeme modellerinin performansları ortalama karesel hatanın karekökü (OKHK), saçılım indeksi (SI), ortalama mutlak hata (OMH), ve Nash-Sutcliffe (NS) istatistikleri kullanılarak belirlenmiştir. OKHK, SI, OMH ve NS istatistiklerinin hesaplanmasında kullanılan eşitlikler aşağıda verilmiştir.

$O K H K=\sqrt{\frac{1}{n} \sum_{i=1}^{n}\left(Q_{g, t}-Q_{m, t}\right)^{2}}$

$S I=\frac{O K H K}{\overline{Q_{g, t}}}$

$O M H=\frac{1}{n} \sum_{t=1}^{n}\left|Q_{g, t-} Q_{m, t}\right|$

$N S=1-\left[\frac{\sum_{t=1}^{n}\left(Q_{g, t}-Q_{m, t}\right)^{2}}{\sum_{t=1}^{n}\left(Q_{g, t}-\overline{Q_{g, t}}\right)^{2}}\right]$

Burada $Q_{g, t}$ gözlem değerini, $Q_{m, t}$ model çıktısını, $\overline{Q_{g, t}}$ gözlem değerlerinin ortalamasını, n veri sayısını temsil etmektedir. Moriasi vd. (2007) yapmış oldukları çalışmada NS istatistiği için model performansının yeterlilik düzeyini belirleyen bir tablo vermişlerdir. Bu aralıklar Tablo 2'de verilmiştir.

Tablo 2: Nash-Sutcliffe etkinlik katsayısı için belirlenen performans aralıkları

\begin{tabular}{ccccc}
\hline Performans & Çok İyi & İyi & Yeterli & Yetersiz \\
\hline NS & $0.75<\mathrm{NS}<1$ & $0.65<\mathrm{NS}<0.75$ & $0.50<\mathrm{NS}<0.65$ & NS $<0.50$ \\
\hline
\end{tabular}

\section{Bulgular ve İrdeleme}

ÇDURE tabanlı kurulmuş olan istatistiksel ölçek indirgeme modellerinde kullanılan atmosferik değişkenler ve bu değişkenlerin modellerdeki önemi Tablo 3'te verilmiştir.

Tablo 3: Atmosferik değişkenlerin modellerdeki önemi

\begin{tabular}{|c|c|c|c|c|c|c|c|c|}
\hline \multicolumn{3}{|l|}{ Akçaabat } & \multicolumn{3}{|l|}{ Bayburt } & \multicolumn{3}{|l|}{ Giresun } \\
\hline & 100 & |||||||||||| $\mid$ & air & 100 & & air & 100 & \\
\hline air200 & 6,8 & || $\mid$ & air850 & 8,71 & $\|||$ & hgt500 & 5,72 & \\
\hline air500 & 5,77 & $\|$ & prate & 8,17 & |il & air200 & 5,37 & $\|$ \\
\hline hgt500 & 4,37 & $\|$ & press & 6,95 & $\|$ & air500 & 5,04 & $\|$ \\
\hline \multirow{2}{*}{ press } & 1,58 & & hgt500 & 6,62 & $\|$ & hgt850 & 4,24 & $\|$ \\
\hline & & & air500 & 6,6 & & rhum 850 & 2,11 & \\
\hline \multicolumn{3}{|c|}{ Gümüşhane } & Hopa & & & Ordu & & \\
\hline & 100 & & air & 100 & & air & 100 & \\
\hline hgt200 & 6,17 & $\|$ & hgt850 & 8,86 & \|\| & hgt850 & 20,2 & \\
\hline \multirow[t]{5}{*}{ hgt 850} & 4,31 & $\|$ & prate & 2,95 & & air200 & 19,23 & \\
\hline & & & air200 & 2,33 & & air500 & 15,6 & In|"1|| \\
\hline & & & hgt500 & 2,33 & & hgt200 & 12,79 & $\|\mid\|\|\|$ \\
\hline & & & slp & 1,79 & & & 6,57 & \|\| \\
\hline & & & & & & air850 & 4,85 & \\
\hline Pazar & & & Rize & & & Suşehri & & \\
\hline air & 100 & & air & 100 & & air & 100 & \\
\hline rhum 850 & 58,63 & |||||||||||||||||||||| & hgt850 & 18,36 & $\||\||\|| \mid$ & hgt500 & 7,85 & $\|$ \\
\hline air850 & 54,57 & |||||||||||||||||||| & prate & 17 & $\|\mid\|\|\| \|$ & rhum500 & 7,43 & $\|$ \\
\hline air200 & 25,77 & '|l||||||" & rhum 850 & 13,85 & ||l|||" & air850 & 4,68 & $\|$ \\
\hline prate & 21,88 & $\|||||$ & press & 12,38 & "In" & rhum 850 & 1,66 & \\
\hline hgt500 & 21,86 & nim & slp & 7,09 & III" & & & \\
\hline
\end{tabular}


Tablo 3’ün devamı

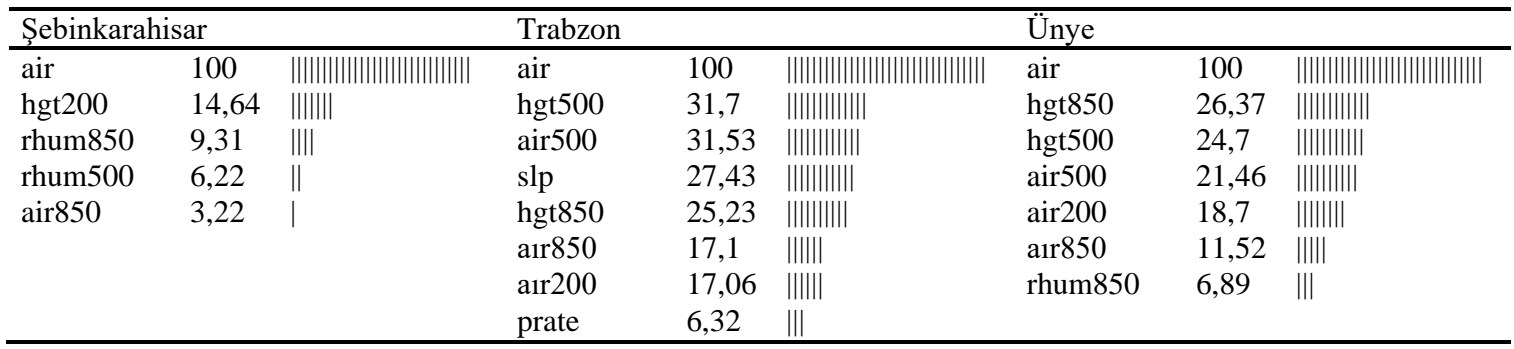

Tablo 3 incelendiğinde tüm istasyonlarda en önemli parametrenin yüzey sıcaklığını temsil eden air atmosferik değişkeni olduğu görülmektedir. Pazar istasyonu dışındaki istasyonların tamamında diğer parametrelerin modellerdeki önemi oldukça düşüktür. Her bir istasyon için ÇDURE tabanlı modellere ait temel fonksiyonları ve bu fonksiyonların birleștirilmesi ile elde edilmiş olan denklemler belirlenmiş, Tablo 4, 5 ve 6'te verilmiştir.

Tablo 4: Akçaabat, Bayburt, Giresun ve Gümüşhane istasyonları modellerine ait temel fonksiyonlar ve denklemler

\begin{tabular}{|c|c|c|c|}
\hline Akçaabat & Bayburt & Giresun & Gümüşhane \\
\hline $\mathrm{BF} 1=$ air +0.220823$)$ & $\mathrm{BF} 1=$ air +0.181845$)$ & $\mathrm{BF} 1=$ air -0.212753$)$ & $\mathrm{BF} 2=-0.0533958-$ air $)$ \\
\hline $\mathrm{BF} 2=-0.220823-$ air $)$ & $\mathrm{BF} 2=-0.181845-$ air $)$ & $\mathrm{BF} 2=0.212753-$ air $)$ & BF4 = $0.341023-$ hgt200); \\
\hline $\mathrm{BF} 3=\mathrm{air}+0.414886)$ & $\mathrm{BF} 4=-0.104402-\operatorname{arr} 850)$ & $\mathrm{BF} 3=\mathrm{air}+0.369679)$ & BF7 = hgt850 + 0.30986) \\
\hline $\mathrm{BF} 6=-0.316273-$ air 500$)$ & $\mathrm{BF} 5=$ prate +2.14282$) * \mathrm{BF} 2$ & $\mathrm{BF} 4=-0.369679-$ air $)$ & $\mathrm{BF} 22=\mathrm{air}+0.121545)$ \\
\hline $\mathrm{BF} 8=-0.267771-\operatorname{hgt} 500)$ & BF9 = $0.629293-$ air $)$ & $\mathrm{BF} 5=$ air $500+0.316273)$ & \\
\hline $\mathrm{BF} 9=$ air -0.160863$)$ & $\mathrm{BF} 10=$ hgt500 + 1.11026) * BF9; & BF7 = hgt500 + 0.157539) & \\
\hline $\mathrm{BF} 20=$ press +1.49635$)$ & $\mathrm{BF} 11=-1.11026-$ hgt500) $* \mathrm{BF} 9$ & $\mathrm{BF} 11$ = rhum $850+3.19402)$ & \\
\hline & $\begin{array}{l}\mathrm{BF} 16=\text { press }+3.16037) * \mathrm{BF} 9 \\
\mathrm{BF} 21=\operatorname{air} 500+1.24267) * \mathrm{BF} 16\end{array}$ & BF16 = hgt850 + 3.32872) & \\
\hline \multirow{2}{*}{\multicolumn{4}{|c|}{$\begin{array}{l}\mathrm{Y}=-0.290939+1.10115 * \mathrm{BF} 1-0.949368 * \mathrm{BF} 2+0.0611297 * \mathrm{BF} 3+0.32177 * \mathrm{BF} 6-0.208836 * \mathrm{BF} 8-0.129847 * \mathrm{BF} 9-0.0185548 * \mathrm{BF} 20 ; \\
\mathrm{Y}=-0.120991+0.925049 * \mathrm{BF} 1-1.5061 * \mathrm{BF} 2+0.492702 * \mathrm{BF} 4+0.0609665 * \mathrm{BF} 5+0.541015 * \mathrm{BF} 10-0.136796 * \mathrm{BF} 11-0.0462681 * \mathrm{BF} 16- \\
\quad 0.100077 * \mathrm{BF} 21 ;\end{array}$}} \\
\hline & & & \\
\hline \multicolumn{4}{|c|}{$\begin{aligned} \mathrm{Y}= & 0.04125+0.888481 * \mathrm{BF}-0.868384 * \mathrm{BF} 2+0.0537573 * \mathrm{BF} 3+0.0745313 * \mathrm{BF} 4+0.199173 * \mathrm{BF} 5-0.0575301 * \mathrm{BF} 7-0.0135383 * \mathrm{BF} 11+ \\
& 0.0126392 * \mathrm{BF} 16 ;\end{aligned}$} \\
\hline
\end{tabular}

Tablo 5: Hopa, Ordu, Pazar ve Rize istasyonları modellerine ait temel fonksiyonlar ve denklemler

\begin{tabular}{|c|c|c|c|}
\hline Hopa & Ordu & Pazar & Rize \\
\hline BF1 = AIR - 0.668729); & $\mathrm{BF} 1=\mathrm{AIR}+0.220823)$ & BF1 = AIR - 0.569654); & $\mathrm{BF} 1=\mathrm{AIR}+0.23187)$ \\
\hline $\mathrm{BF} 2=0.668729-\mathrm{AIR})$ & BF3 = HGT850 + 0.615597) & $\mathrm{BF} 2=0.569654-\mathrm{AIR})$ & $\mathrm{BF} 2=-0.23187-\mathrm{AIR})$ \\
\hline $\mathrm{BF} 3=\mathrm{HGT} 850+1.34689)$ & $\mathrm{BF} 4=-0.615597-\mathrm{HGT} 850)$ & $\mathrm{BF} 6=1.06339-\mathrm{HGT} 500)$ & $\mathrm{BF} 3=\mathrm{HGT} 850-0.542235)$ \\
\hline $\mathrm{BF} 4=-1.34689-\mathrm{HGT} 850)$ & BF5 = AIR200 + 0.532032); & BF7 = RHUM850 + 1.2437); & BF4 = 0.542235 - HGT850); \\
\hline $\mathrm{BF} 6=0.196096-\mathrm{PRATE}) * \mathrm{BF} 4$ & BF6 = -0.532032 - AIR200); & BF8 = -1.2437 - RHUM850); & BF5 = PRESS - 1.07415); \\
\hline $\mathrm{BF} 8=-0.936517-\mathrm{SLP}) * \mathrm{BF} 2$ & $\mathrm{BF} 7=\mathrm{AIR}+0.080075)$ & BF9 = PRATE + 1.87631) & BF6 = $1.07415-$ PRESS $)$ \\
\hline BF9 = HGT500 - 1.06339) & $\mathrm{BF} 10=-0.357283-\mathrm{AIR})$ & $\mathrm{BF} 10=\mathrm{AIR} 200+0.442195)$ & BF7 = RHUM850 + 3.19402); \\
\hline $\mathrm{BF} 15=\mathrm{AIR} 200+1.78804) * \mathrm{BF} 9$ & $\mathrm{BF} 12=1.42902-\mathrm{SLP})$ & $\mathrm{BF} 12$ = AIR850 + 2.22087); & $\mathrm{BF} 8=\mathrm{PRATE}+1.65054)$ \\
\hline & BF13 = AIR500 - 0.245249); & & BF10 = AIR - 0.129691) \\
\hline & $\mathrm{BF} 14=0.245249-\mathrm{AIR} 500)$ & & \\
\hline & BF15 = HGT200 - 0.16138); & & \\
\hline & BF18 = -0.210371 - AIR850); & & \\
\hline & $\mathrm{BF} 20=-0.687139-\mathrm{AIR} 200)$ & & \\
\hline \multicolumn{4}{|c|}{$\mathrm{Y}=0.775982+0.909679 * \mathrm{BF} 1-0.990033 * \mathrm{BF} 2-0.0851237 * \mathrm{BF} 3-0.1337 * \mathrm{BF} 4+0.624176 * \mathrm{BF} 6+0.913771 * \mathrm{BF} 8+0.113822 * \mathrm{BF} 15$} \\
\hline \multicolumn{4}{|c|}{$\begin{aligned} \mathrm{Y}= & -0.60189+2.1682 * \mathrm{BF} 1+0.0243268 * \mathrm{BF} 3-0.10758 * \mathrm{BF} 4+0.0944 * \mathrm{BF} 5+0.242958 * \mathrm{BF} 6-1.24495 * \mathrm{BF} 7-0.775413 * \mathrm{BF} 10+0.0666013 * \\
& \mathrm{BF} 12+0.348568 * \mathrm{BF} 13+0.0926918 * \mathrm{BF} 14-0.310086 * \mathrm{BF} 15-0.0949545 * \mathrm{BF} 18-0.209756 * \mathrm{BF} 20 ;\end{aligned}$} \\
\hline \multicolumn{4}{|c|}{$\begin{aligned} \mathrm{Y}= & -0.399945+0.651113 * \mathrm{BF} 1-0.756357 * \mathrm{BF} 2+0.0972645 * \mathrm{BF} 6+0.0518919 * \mathrm{BF} 7-0.120516 * \mathrm{BF} 8-0.0242326 * \mathrm{BF} 9+0.0563613 * \mathrm{BF} 10+ \\
& 0.309506 * \mathrm{BF} 12 ;\end{aligned}$} \\
\hline \multicolumn{4}{|c|}{$\begin{aligned} \mathrm{Y}= & -1.99146+1.09465 * \mathrm{BF} 1-0.944975 * \mathrm{BF} 2+0.081166 * \mathrm{BF} 3-0.150298 * \mathrm{BF} 4-0.6368 * \mathrm{BF} 5+0.69032 * \mathrm{BF} 6+0.026467 * \mathrm{BF} 7-0.0254998 * \mathrm{BF} 8 \\
& -0.18781 * \mathrm{BF} 10+0.578925 * \mathrm{BF} 12 ;\end{aligned}$} \\
\hline
\end{tabular}


Tablo 6: Suşehri, Şebinkarahisar, Trabzon ve Ünye istasyonları modellerine ait temel fonksiyonlar ve denklemler

\begin{tabular}{|c|c|c|c|}
\hline Suşehri & Şebinkarahisar & Trabzon & Ünye \\
\hline BF1 =AIR + 0.386891); & BF1 =AIR + 0.386891); & BF1 =AIR - 0.370563); & BF1 =AIR - 0.212753); \\
\hline $\mathrm{BF} 2=-0.386891-\mathrm{AIR})$ & $\mathrm{BF} 2=-0.386891-\mathrm{AIR})$ & $\mathrm{BF} 2=0.370563-\mathrm{AIR})$ & $\mathrm{BF} 2=0.212753-\mathrm{AIR})$ \\
\hline BF3 =RHUM850 + 1.5216); & BF3 =RHUM850 + 2.97473); & BF3 =HGT850 - 0.452566); & BF3 =AIR200 + 0.399846); \\
\hline $\mathrm{BF} 5=\mathrm{AIR} 850+0.303416)$ & BF5 $=0.624226-$ HGT200) & $\mathrm{BF} 4=0.452566-\mathrm{HGT} 850)$ & $\mathrm{BF} 4=-0.399846-\mathrm{AIR} 200)$; \\
\hline $\mathrm{BF} 7=\mathrm{AIR}+1.5757)$ & BF6 = RHUM500 + 1.61316); & BF6 =-0.414886 - AIR200); & BF6 =-1.01931 - AIR850); \\
\hline BF9 =RHUM500 - 1.43223); & BF9 =0.569285 - AIR850) & BF7 =AIR500 + 0.316273) & BF7 =RHUM850 + 3.19402); \\
\hline BF10 = 1.43223 - RHUM500); & & $\mathrm{BF} 9=\mathrm{SLP}+1.09635)$ & $\mathrm{BF} 8=\mathrm{AIR} 500+0.316273)$ \\
\hline BF11 =HGT500 + 0.4259) & & BF10 =-1.09635 - SLP); & $\mathrm{BF} 10=\mathrm{HGT} 500+0.0598177)$ \\
\hline BF12 =-0.4259 - HGT500); & & BF12 =-0.95774 - AIR500); & BF11 =-0.0598177 - HGT500); \\
\hline & & BF14 =1.00155 - HGT500); & BF13 = 1.97998 - HGT850) \\
\hline & & BF15 =PRATE + 1.09342); & \\
\hline & & BF17 =AIR850 - 1.07878); & \\
\hline \multicolumn{4}{|c|}{$\begin{aligned} \mathrm{Y}= & 0.195695+1.23309 * \mathrm{BF} 1-1.59755 * \mathrm{BF} 2-0.0159648 * \mathrm{BF} 3+0.244622 * \mathrm{BF} 5-0.448228 * \mathrm{BF} 7+0.219205 * \mathrm{BF} 9+0.0547446 * \mathrm{BF} 10- \\
& 0.129466 * \mathrm{BF} 11+0.0577889 * \mathrm{BF} 12 ;\end{aligned}$} \\
\hline \multicolumn{4}{|c|}{$\mathrm{Y}=-0.337254+1.02489 * \mathrm{BF} 1-1.05933 * \mathrm{BF} 2-0.0263131 * \mathrm{BF} 3+0.196369 * \mathrm{BF} 5-0.0391668 * \mathrm{BF} 6-0.103764 * \mathrm{BF} 9$} \\
\hline \multicolumn{4}{|c|}{$\begin{aligned} \mathrm{Y}= & 0.122824+0.871136 * \mathrm{BF} 1-0.978768 * \mathrm{BF} 2+0.121621 * \mathrm{BF} 3-0.190524 * \mathrm{BF} 4+0.0637173 * \mathrm{BF} 6+0.286813 * \mathrm{BF} 7-0.165632 * \mathrm{BF} 9+ \\
& 0.419767 * \mathrm{BF} 10-0.16704 * \mathrm{BF} 12+0.369366 * \mathrm{BF} 14-0.0130943 * \mathrm{BF} 15-0.286167 * \mathrm{BF} 17 ;\end{aligned}$} \\
\hline \multicolumn{4}{|c|}{$\begin{aligned} \mathrm{Y}= & 0.239138+1.13366 * \mathrm{BF} 1-1.04099 * \mathrm{BF} 2+0.0566214 * \mathrm{BF} 3+0.0986179 * \mathrm{BF} 4-0.142514 * \mathrm{BF} 6-0.0162192 * \mathrm{BF} 7+0.402722 * \mathrm{BF} 8- \\
& 0.525411 * \mathrm{BF} 10+0.31314 * \mathrm{BF} 11-0.0879745 * \mathrm{BF} 13 ;\end{aligned}$} \\
\hline
\end{tabular}

$\mathrm{Bu}$ eşitliklerde BF: her bir parametre için oluşturulmuş temel fonksiyonları, Y: ÇDURE model çıktısı olan sıcaklık değerini ifade etmektedir. EraInterim veri setinde yer alan atmosferik değişkenlerin bağımsız değişkenler olarak ve meteoroloji istasyonlarından ölçülmüş olan aylık ortalama sıcaklık değerlerinin bağımlı değişken olarak kullanıldığı ÇDURE tabanlı ve istasyon özelinde kurulmuş olan istatistiksel ölçek indirgeme model performans istatistikleri eğitim ve test veri takımları için ayrı ayrı hesaplanmıştır. Eğitim veri takımı için hesaplanmış olan model performans istatistikleri Tablo 7'de, test veri takımı için ise Tablo 8'de verilmiştir.

Tablo 7: Eralnterim re-analiz verileri kullanılarak kurulan ÇDURE modellerinin eğitim veri takımı model performans istatistikleri

\begin{tabular}{lcccccccccccc}
\hline Sicaklık & \multicolumn{10}{c}{ Ĕ̆itim veri takımı } \\
\hline İstasyon & Akç. & Bay. & Gir. & Güm. & Hopa & Ordu & Pazar & Rize & Suş. & Şeb. & Trab. & Ünye \\
\hline OKHK & 0,440 & 0,723 & 0,474 & 0,503 & 0,768 & 0,384 & 0,446 & 0,389 & 0,518 & 0,555 & 0,426 & 0,427 \\
SI & 0,031 & 0,108 & 0,033 & 0,054 & 0,054 & 0,027 & 0,034 & 0,028 & 0,053 & 0,062 & 0,029 & 0,030 \\
OMH & 0,345 & 0,538 & 0,367 & 0,407 & 0,565 & 0,307 & 0,346 & 0,308 & 0,391 & 0,433 & 0,334 & 0,335 \\
NS & 0,995 & 0,994 & 0,994 & 0,996 & 0,983 & 0,996 & 0,994 & 0,996 & 0,996 & 0,995 & 0,995 & 0,995 \\
\hline
\end{tabular}

Tablo 8: Eralnterim re-analiz verileri kullanılarak kurulan ÇDURE modellerinin test veri takımı model performans istatistikleri

\begin{tabular}{lcccccccccccc}
\hline Sicaklık & \multicolumn{10}{c}{ Test veri takımı } \\
\hline İstasyon & Akç. & Bay. & Gir. & Güm. & Hopa & Ordu & Pazar & Rize & Suş. & Şeb. & Trab. & Ünye \\
\hline OKHK & 0,571 & 0,760 & 0,877 & 0,591 & 1,210 & 0,533 & 0,498 & 0,452 & 0,602 & 0,591 & 0,436 & 0,630 \\
SI & 0,037 & 0,099 & 0,058 & 0,058 & 0,080 & 0,035 & 0,035 & 0,030 & 0,056 & 0,058 & 0,028 & 0,042 \\
OMH & 0,470 & 0,600 & 0,628 & 0,461 & 0,894 & 0,443 & 0,400 & 0,371 & 0,476 & 0,456 & 0,350 & 0,495 \\
NS & 0,992 & 0,993 & 0,979 & 0,995 & 0,967 & 0,993 & 0,993 & 0,995 & 0,995 & 0,995 & 0,995 & 0,990 \\
\hline
\end{tabular}

Eğitim ve test veri takımları için hesaplanan NS değerleri tüm istasyonlarda 0,9 değerinden büyüktür. Bu değerler Tablo 2'ye göre değerlendirilecek olduğunda ÇDURE tabanlı istatistiksel ölçek indirgeme modeli performanslarının tüm istasyonlar için çok iyi sınıfında yer aldığı görülmektedir. Ayrıca eğitim veri takımına ait hata değerlerinin test veri takımına kıyasla daha yüksek olduğu görülmektedir. Eğitim ve test veri takımlarında en yüksek hata değerleri Hopa istasyonu için elde edilmiştir. Model sonuçları ve gözlem değerlerine ait bazı temel istatistikler arasındaki uyumun belirlenebilmesi için eğitim ve test gruplarına ait ortalama (Ort), maksimum (Mak), minimum (Min), standart sapma (Stn), çarpıklık (Çar) ve basıklık (Bas) temel istatistikleri hesaplanmış ve karşılaştırılmıştır (Tablo 9). Tablo incelenecek olduğunda tüm istasyonlar için gözlem verilerinin eğitim ve test veri takımları için hesaplanan temel istatistiklerin model çıktıları ile çok yakın olduğu görülmektedir. Test veri takımı için çalışma kapsamında belirlenmiş olan tüm istasyonlara ait test veri takımı saçılım grafikleri Şekil 5'te verilmiştir. 
Tablo 9: Gözlem verileri ve model çıktılarına ait temel istatistikler

\begin{tabular}{|c|c|c|c|c|c|c|c|c|c|c|c|c|c|}
\hline \multirow{2}{*}{$\begin{array}{l}\text { Veri Takımı } \\
\text { İstasyon }\end{array}$} & \multicolumn{7}{|c|}{ Eğitim } & \multicolumn{6}{|c|}{ Test } \\
\hline & İstatistik & Ort. & Mak. & Min. & Stn. & Çar. & Bas. & Ort. & Mak. & Min. & Stn. & Çar. & Bas. \\
\hline \multirow{2}{*}{ Akçaabat } & Gözlem & 14,14 & 25,30 & 3,10 & 6,16 & 0,13 & $-1,33$ & 15,24 & 26,30 & 4,10 & 6,31 & 0,15 & $-1,29$ \\
\hline & Model & 14,14 & 25,34 & 3,47 & 6,14 & 0,13 & $-1,34$ & 14,97 & 26,69 & 4,33 & 6,52 & 0,18 & $-1,34$ \\
\hline \multirow{2}{*}{ Bayburt } & Gözlem & 6,69 & 22,50 & $-11,00$ & 8,98 & $-0,22$ & $-1,23$ & 7,65 & 22,50 & $-11,70$ & 9,21 & $-0,24$ & $-1,04$ \\
\hline & Model & 6,69 & 21,20 & $-10,96$ & 8,95 & $-0,21$ & $-1,27$ & 7,50 & 22,61 & $-12,11$ & 9,35 & $-0,23$ & $-1,07$ \\
\hline \multirow{2}{*}{ Giresun } & Gözlem & 14,39 & 25,50 & 3,50 & 6,02 & 0,11 & $-1,30$ & 15,11 & 27,00 & 4,00 & 6,10 & 0,16 & $-1,21$ \\
\hline & Model & 14,39 & 25,13 & 3,70 & 5,97 & 0,13 & $-1,32$ & 15,12 & 26,63 & 4,72 & 6,32 & 0,20 & $-1,31$ \\
\hline \multirow{2}{*}{ Gümüşhane } & Gözlem & 9,39 & 22,80 & $-6,20$ & 7,96 & $-0,15$ & $-1,28$ & 10,18 & 24,20 & $-6,10$ & 8,06 & $-0,08$ & $-1,16$ \\
\hline & Model & 9,39 & 22,59 & $-5,64$ & 7,94 & $-0,14$ & $-1,30$ & 10,12 & 23,95 & $-6,72$ & 8,30 & $-0,13$ & $-1,17$ \\
\hline \multirow{2}{*}{ Hopa } & Gözlem & 14,25 & 26,00 & 2,70 & 5,89 & 0,06 & $-1,18$ & 15,09 & 28,30 & 2,00 & 6,62 & 0,10 & $-1,10$ \\
\hline & Model & 14,25 & 25,06 & 2,45 & 5,84 & 0,06 & $-1,21$ & 15,13 & 26,79 & 3,73 & 6,25 & 0,13 & $-1,14$ \\
\hline \multirow{2}{*}{ Ordu } & Gözlem & 14,20 & 25,50 & 3,00 & 6,20 & 0,14 & $-1,32$ & 15,23 & 26,70 & 4,20 & 6,41 & 0,18 & $-1,29$ \\
\hline & Model & 14,20 & 25,36 & 2,84 & 6,19 & 0,14 & $-1,32$ & 15,04 & 26,88 & 4,55 & 6,56 & 0,21 & $-1,32$ \\
\hline \multirow{2}{*}{ Pazar } & Gözlem & 13,19 & 24,10 & 2,10 & 5,96 & 0,04 & $-1,29$ & 14,10 & 24,70 & 2,40 & 6,17 & 0,07 & $-1,25$ \\
\hline & Model & 13,19 & 23,67 & 2,54 & 5,95 & 0,04 & $-1,31$ & 13,92 & 24,95 & 2,56 & 6,30 & 0,09 & $-1,28$ \\
\hline \multirow{2}{*}{ Rize } & Gözlem & 14,13 & 25,60 & 3,10 & 6,26 & 0,09 & $-1,33$ & 15,23 & 27,00 & 3,70 & 6,58 & 0,12 & $-1,32$ \\
\hline & Model & 14,13 & 25,58 & 3,28 & 6,25 & 0,09 & $-1,34$ & 14,97 & 26,76 & 3,48 & 6,65 & 0,13 & $-1,34$ \\
\hline \multirow{2}{*}{ Suşehri } & Gözlem & 9,83 & 23,00 & $-7,80$ & 8,08 & $-0,20$ & $-1,23$ & 10,77 & 24,80 & $-6,50$ & 8,20 & $-0,12$ & $-1,10$ \\
\hline & Model & 9,83 & 23,64 & $-6,76$ & 8,07 & $-0,19$ & $-1,23$ & 10,64 & 24,35 & $-7,68$ & 8,35 & $-0,18$ & $-1,09$ \\
\hline \multirow{2}{*}{ Şebinkarahisar } & Gözlem & 8,98 & 22,90 & $-7,20$ & 8,08 & $-0,15$ & $-1,25$ & 10,16 & 24,60 & $-6,40$ & 8,06 & $-0,07$ & $-1,15$ \\
\hline & Model & 8,98 & 23,10 & $-6,39$ & 8,06 & $-0,15$ & $-1,27$ & 9,83 & 23,94 & $-6,92$ & 8,29 & $-0,09$ & $-1,16$ \\
\hline \multirow{2}{*}{ Trabzon } & Gözlem & 14,55 & 26,00 & 3,80 & 6,04 & 0,10 & $-1,28$ & 15,34 & 27,00 & 3,80 & 6,37 & 0,14 & $-1,27$ \\
\hline & Model & 14,55 & 25,55 & 3,58 & 6,02 & 0,11 & $-1,28$ & 15,37 & 26,97 & 4,17 & 6,37 & 0,18 & $-1,25$ \\
\hline \multirow{2}{*}{ Ünye } & Gözlem & 14,10 & 25,40 & 3,20 & 6,09 & 0,15 & $-1,28$ & 15,16 & 26,90 & 4,20 & 6,42 & 0,16 & $-1,30$ \\
\hline & Model & 14,10 & 25,33 & 3,15 & 6,07 & 0,15 & $-1,30$ & 14,86 & 26,85 & 4,21 & 6,44 & 0,23 & $-1,30$ \\
\hline
\end{tabular}



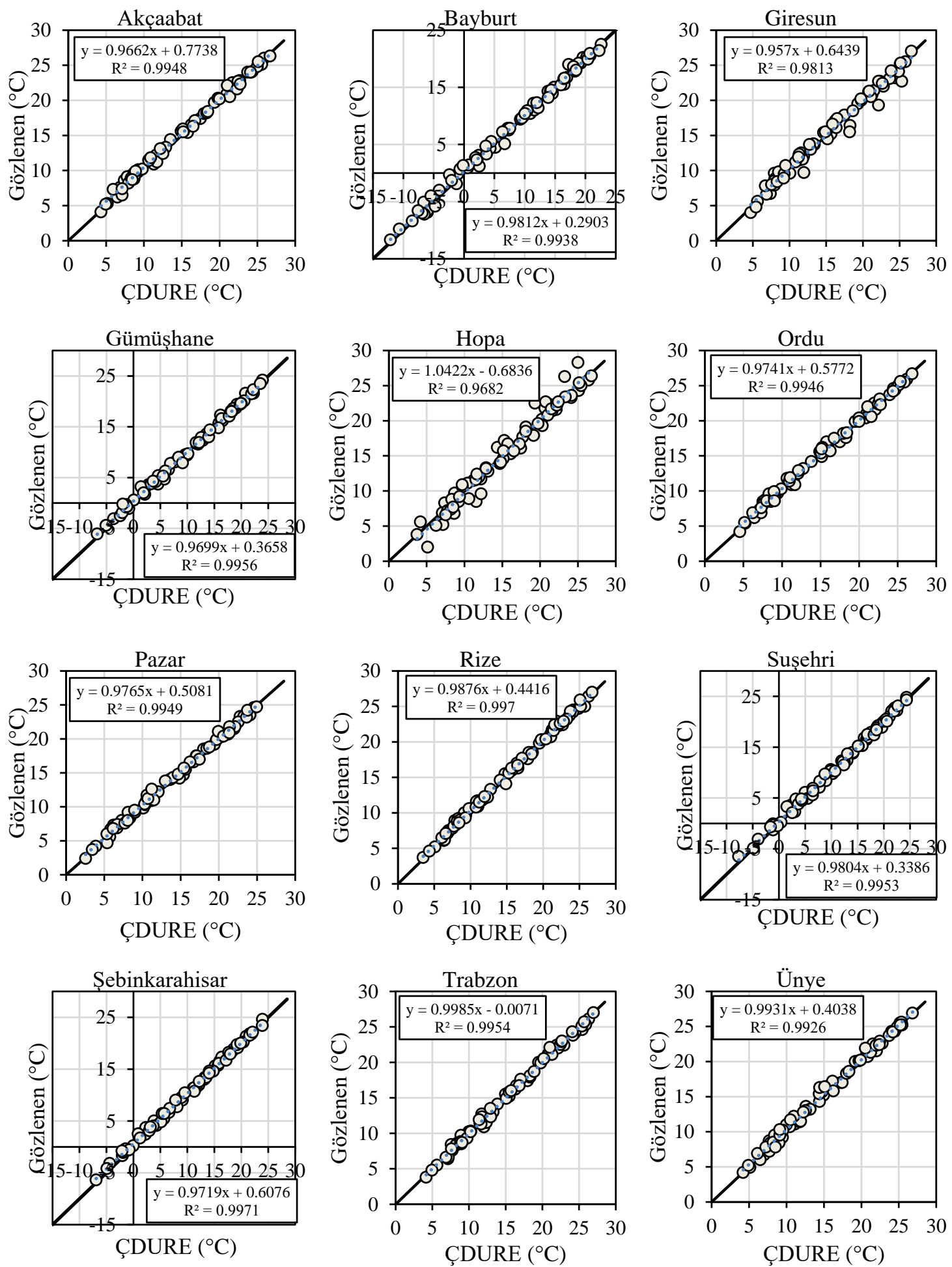

Şekil 5: Trabzon ve Bayburt istasyonları test veri takımına ait saçılım grafikleri

Saçılım grafiklerinde verilerin köşegen üzerine sıralanması model performansının yüksek olduğunu ve köşegen üzerindeki verilerin nispi hatalarının sıfır olduğunu ifade etmektedir (Bayram vd. 2015). Şekil 5 incelendiğinde verilerin birçoğunun köşegen üzerinde olduğu görülmektedir. $\mathrm{Bu}$ durum model performanslarının yüksek olduğunu göstermektedir. Ayrıca verilerin dağılımına uygun çizilen eğrinin hesaplanan $\mathrm{R}^{2}$ değerleri 1'e oldukça yakındır. Ölçek indirgeme model sonuçları ile gözlem değerlerinin havza genelindeki dağılımının görülebilmesi için test veri takımına ait yıllık ortalama yağış değerlerinin bölgesel ölçekte hazırlanan haritaları Şekil 6'da verilmiştir. Ayrıca yıllık ortalama tahmin değerleri ile gözlem değerleri arasındaki farkın net bir şekilde görülebilmesi için farkları alınmış, \% olarak haritalandırılmış ve Şekil 7'de verilmiştir. 


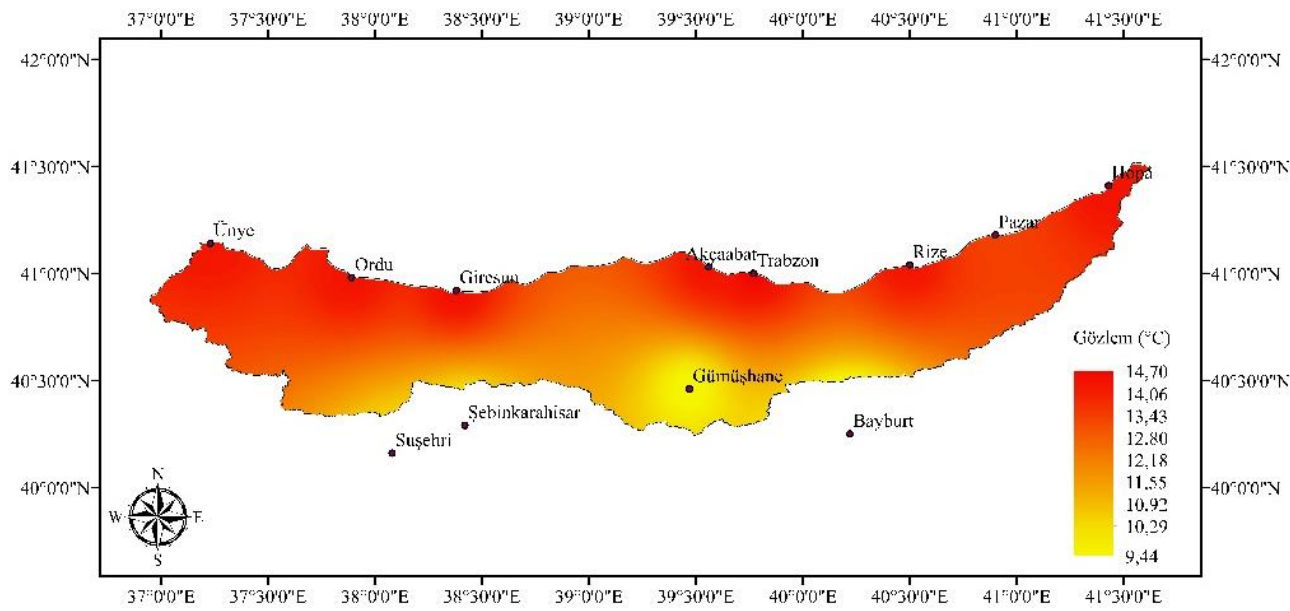

(a)

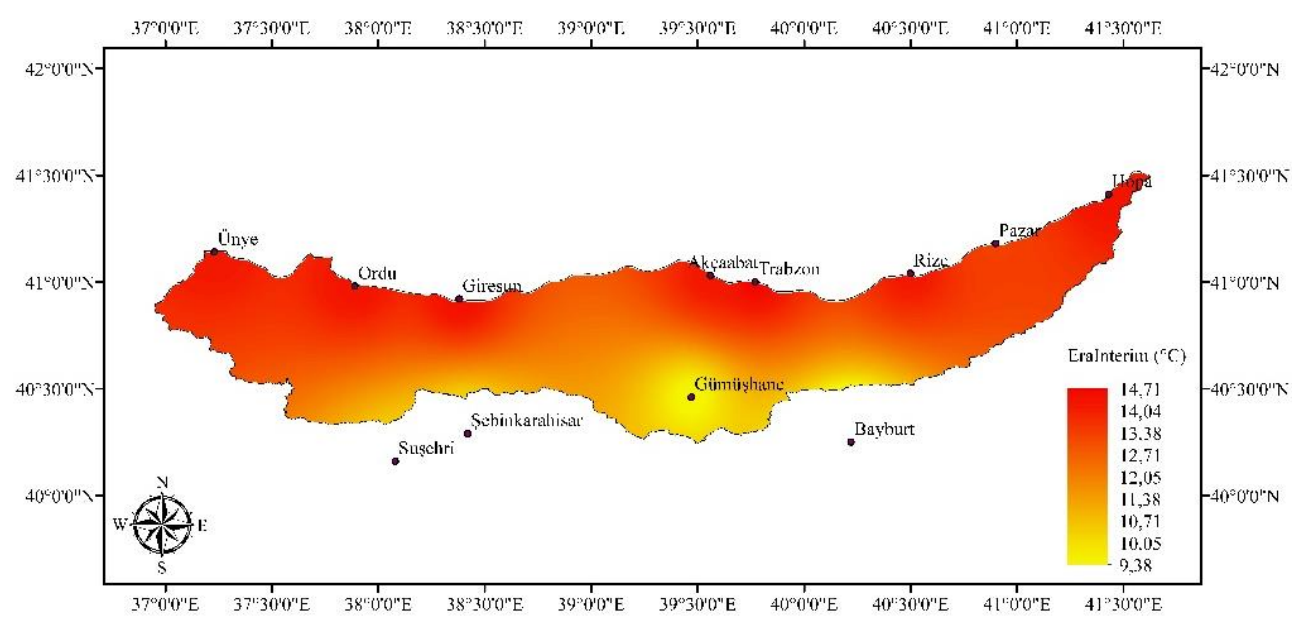

(b)

Şekil 6: Test veri takımına ait yıllık ortalama sıcaklık haritaları (a) Gözlem (b) ÇDURE

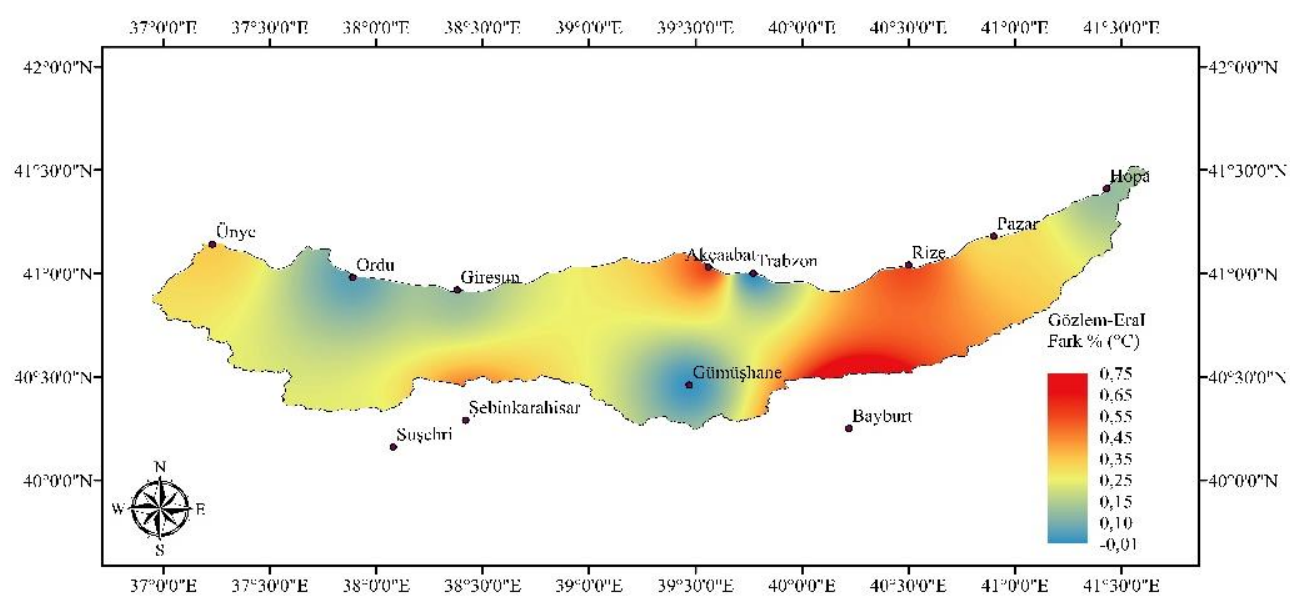

Şekil 7: Test veri takımına yıllık ortalama sıcaklık gözlem ve tahmin değerleri \% farkı

Hazırlanmış olan haritalar incelendiğinde havza genelinde gözlem değerleri ile ölçek indirgeme model çıktılarının birbirine oldukça yakın olduğu görülmektedir. Gözlem değerleri ile model çıktıları arasındaki farkın en yüksek değerinin \%0,75 ile Bayburt istasyonunda olduğu görülmektedir. 


\section{Sonuçlar}

$\mathrm{Bu}$ çalışmada EraInterim re-analiz veri takımında yer alan küresel ölçekli atmosferik değişkenler kullanılarak Doğu Karadeniz Havzası meteoroloji istasyonlarından ölçülmüş olan aylık ortalama sıcaklık değerleri ÇDURE tabanlı istatistiksel ölçek indirgeme yöntemi yardımıyla tahmin edilmiştir. Bu amaçla EraInterim re-analiz veri takımında yer alan 12 adet atmosferik değişken ve Doğu Karadeniz Havzası ve çevresinde yer alan, en az 30 yıllık (1981-2010) kesintisiz gözlem verisine sahip 12 adet meteoroloji istasyonundan ölçülmüş aylık ortalama sıcaklık verileri kullanılmıştır. Bu çalışma iklim değişikliği etki çalışmalarında küresel ölçekli verilerin yerel ölçekteki karşılıklarının belirlenmesinde kullanılan istatistiksel ölçek indirgeme yönteminin Doğu Karadeniz Havzası için uygulandığı ilk çalışma olma özelliğini taşımaktadır. Yapılan modelleme çalışmaları sonucunda gözlem değerleri ile model çıktıları çeşitli performans istatistikleri kullanılarak karşılaştırılmıştır. Hesaplanan performans istatistiklerine göre ÇDURE istatistiksel ölçek indirgeme yöntemi aylık ortalama sıcaklık parametresi için küresel ölçekli atmosferik değişkenleri istasyon ölçeğine havzadaki tüm istasyonlarda başarılı bir şekilde indirgediği görülmüştür. Havza genelinde en yüksek farklılığın Bayburt istasyonu için olduğu, diğer istasyonlarda ise gözlem değerleri ile model çıktılarının birbirine oldukça yakın olduğu hesaplanan temel istatistikler yardımıyla belirlenmiştir. EraInterim re-analiz veri takımından seçilen 12 adet atmosferik değişken arasından yüzey sıcaklığını temsil eden air parametresinin tüm istasyonlar için kurulan modellerdeki öneminin \%100 olduğu görülmüştür. Diğer parametrelerin ise modellerde çok düşük önem seviyelerinde yer aldığı görülmüştür. Bu durum sıcaklık parametresinin modellenmesinde sadece air değişkeni kullanılarak da başarılı sonuçlar elde edilebileceğini göstermektedir.

$\mathrm{Bu}$ çalışma kapsamında EraInterim re-analiz verileri kullanılmıştır. Doğu Karadeniz Havzası için farklı re-analiz veri takımları ile bu çalışmadan elde edilen sonuçlar karşılaştırılabilir. Ayrıca farklı istatistiksel ölçek indirgeme yöntemleri uygulanarak havza için en uygun ölçek indirgeme yöntemi farklı iklim parametreleri için belirlenerek GDM çıktılarının gelecek dönem verileri havza ölçeğinde değerlendirilebilir. Yazarların bu konudaki çalışmaları devam etmektedir. Bu çalışmadan elde edilen sonuçların iklim değişikliğinin gelecek dönemlerde Doğu Karadeniz Havzası üzerindeki etkisini belirlemeye yönelik yapılacak olan çalışmalarda araştırmacılara bir altlık sağlayacağı düşünülmektedir.

\section{Teşekkür}

Bu çalışma, Sinan Nacar tarafından, Karadeniz Teknik Üniversitesi, Fen Bilimleri Enstitüsü, İnşaat Mühendisliği Anabilim Dalı, doktora programında hazırlanmış olan tez çalışmasının bir kısmını kapsamaktadır.

\section{Kaynaklar}

Akhter M.S., Shamseldin A.Y., Melville B.W., (2019), Comparison of dynamical and statistical rainfall downscaling of CMIP5 ensembles at a small urban catchment scale, Stochastic Environmental Research and Risk Assessment, 33(4-6), 989-1012.

Atay H., (2015), Kizllırmak Havzasının 2013-2040 Periyodunda İklim İndisleri Projeksiyonları, Yüksek Lisans Tezi, Ankara Üniversitesi, Sosyal Bilimler Enstitüsü, Ankara.

Bayraç H.N., Doğan E., (2016), Türkiye'de iklim değişikliğinin tarım sektörü üzerine etkileri, Eskişehir Osmangazi Üniversitesi İ̈BF Dergisi, 11(1), 23-48.

Bayram A., Uzlu E., Kankal M., Dede T., (2015), Modeling stream dissolved oxygen concentration using teaching-learning based optimization algorithm, Environmental Earth Sciences, 73, 6565-6576.

Berrisford P., Dee D., Fielding K., Fuentes M., Kallberg P., Kobayashi S., Uppala S., (2009), The ERA-interim archive, ERA report series no.1, Shinfield Park, Reading, Berkshire RG2 9AX, United Kingdom, 16ss.

Berrisford P., Kallberg P., Kobayashi S., Dee D.P., Uppala S.M., Simmons A.J., Poli P., Sato H., (2011), Atmospheric conservation properties in ERA-Interim, Quarterly Journal of the Royal Meteorological Society, 137(659), 1381-1399.

Chen H., Xu C.Y., Guo S., (2012), Comparison and evaluation of multiple GCMs, statistical downscaling and hydrological models in the study of climate change impacts on runoff, Journal of Hydrology, 434, 36-45.

Crane R.G., Hewitson B.C., (1998), Doubled CO2 precipitation changes for the Susquehanna Basin: Down-scaling from the Genesis general circulation model, International Journal of Climatology: A Journal of the Royal Meteorological Society, 18(1), 65-76.

Çınaklı M., (2008), Doğu Karadeniz bölümü’nde meydana gelen taşkınlar, Yüksek Lisans Tezi, Ankara Üniversitesi, Sosyal Bilimler Enstitüsü, Ankara.

Dee D.P., Uppala S.M., Simmons A.J., Berrisford P., Poli P., Kobayashi S., Andrae U., Balmaseda M.A., Balsamo G., et al., (2011), The ERA-Interim reanalysis: Configuration and performance of the data assimilation system, Quarterly Journal of the Royal Meteorological Society, 137(656), 553-597.

Demir Ö., Atay H., Eskioğlu O., Tuvan A., Demircan M., Akçakaya A., (2013), RCP4.5 Senaryosuna göre Türkiye'de sıcaklık ve yă̆lş projeksiyonları, III. Türkiye İklim Değişikliği Kongresi (TIKXEK 2013), 3-5 Haziran, İstanbul.

Demircan M., Demir Ö., Atay H., Eskioğlu O., Yazıcı B., Gürkan H., Tuvan A., Akçakaya A., (2014), Türkiye'de yeni senaryolara göre iklim değişikliği projeksiyonları, TÜCAUM VIII. Coğrafya Sempozyumu, 23-24 Ekim, Ankara.

Fistikoglu O., Okkan U., (2010), Statistical downscaling of monthly precipitation using NCEP/NCAR reanalysis data for Tahtali River Basin in Turkey, Journal of Hydrologic Engineering, 16(2), 157-164. 
Fowler H.J., Ekström M., Kilsby C.G., Jones P.D., (2005), New estimates of future changes in extreme rainfall across the UK using regional climate model integrations. 1. Assessment of control climate, Journal of Hydrology, 300(1-4), 212-233.

Frei C., Christensen J.H., Deque M., Jacob D., Jones R.G., Vidale P.L., (2003), Daily precipitation statistics in regional climate models: Evaluation and intercomparison for the European Alps, Journal of Geophysical Research: Atmospheres, 108(D3), 4124, doi:10.1029/2002JD002287.

Friedman J.H., (1991), Multivariate adaptive regression splines, The Annals of Statistics, 19(1), 1-67.

Hamlet A.F., Byun K., Robeson S.M., Widhalm M., Baldwin M., (2019), Impacts of climate change on the state of Indiana: ensemble future projections based on statistical downscaling, Climatic Change, 1-15.

Horton P., Brönnimann S., Weingartner R., (2018), Impact of the choice of a reanalysis dataset on statistical downscaling of precipitation, EGU General Assembly, Geophysical Research Abstracts, Vol. 20, EGU2018-14297, ss.14297.

IPCC, (2013), Climate Change 2013: The Physical Science Basis. Contribution of Working Group I to the Fifth Assessment Report of the Intergovernmental Panel on Climate Change, Cambridge University Press, Cambridge, United Kingdom and New York, NY, USA, 1535ss.

IPCC, (2018), Summary for Policymakers. In: Global Warming of $1.5^{\circ} \mathrm{C}$, https://www.ipcc.ch/site/assets/uploads/sites/2/2019/05/ SR15_SPM_version_report_LR.pdf, [Erişim 1 Mart 2020].

Kisi O., Parmar K.S., (2016), Application of least square support vector machine and multivariate adaptive regression spline models in long term prediction of river water pollution, Journal of Hydrology, 534, 104-112

Mearns L.O., Bogardi I., Giorgi F., Matyasovszky I., Palecki M., (1999), Comparison of climate change scenarios generated from regional climate model experiments and statistical downscaling, Journal of Geophysical Research: Atmospheres, 104(D6), 66036621.

MGM, (2015), Yeni senaryolar ile Türkiye iklim projeksiyonları ve iklim değişikliği, Araştırma Dairesi Başkanlığı Klimatoloji Şube Müdürlüğ̈̈, Meteoroloji Genel Müdürlüğü Matbaası, Ankara.

Moriasi D.N., Arnold J.G., Van Liew M.W., Bingner R.L., Harmel R.D., Veith T.L., (2007), Model evaluation guidelines for systematic quantifcation of accuracy in watershed simulations, Transactions of the ASABE, 50(3): 885-900.

Murakami H., (2014), Tropical cyclones in reanalysis data sets, Geophysical Research Letters, 41(6), 2133-2141.

Nacar S., Satilmis U., (2017), Temporal variation of organic and inorganic carbon transport from the Southeastern Black Sea (Trabzon Province) rivers, European Journal of Engineering and Natural Sciences, 2(1), 149-153.

Nacar S., Kankal M., Okkan U., Dede T., (2019), İstatistiksel ölçek indirgeme yöntemi ile NCEP/NCAR re-analiz verilerinin Doğu Karadeniz havzası aylı yă̆ış ve sıcaklık değerlerine indirgenmesi, International Conference on Innovation, Sustainability, Technology and Education in Civil Engineering (iSTE-CE’2019), 13-15 June, Iskenderun Technical University, Iskenderun Hatay, Turkey, ss.470-483.

Nacar S., Kankal M., Hınıs M.A., (2018), Çok değişkenli uyarlanabilir regresyon eğrileri (ÇDURE) ile Günlük Akarsu Akımlarının Tahmini-Haldizen Deresi Örneği, Gümüşhane Üniversitesi Fen Bilimleri Enstitüsü Dergisi, 8(1), 38-47.

Okkan U., Karakan E., (2016), İklim değişikliğinin ikizcetepeler barajı akımlarına etkilerinin modellenmesi: 2015-2030 projeksiyonu, Teknik Dergi, 27(2), 7379-7401.

Okkan U., Kirdemir U., (2016), Downscaling of monthly precipitation using CMIP5 climate models operated under RCPs, Meteorological Applications, 23(3), 514-528.

Okkan U., Kirdemir U., (2018), Investigation of the behavior of an agricultural-operated dam reservoir under RCP scenarios of AR5-IPCC, Water resources management, 32(8), 2847-2866.

Okkan U., Fistikoglu O., (2014), Evaluating climate change effects on runoff by statistical downscaling and hydrological model GR2M, Theoretical and applied climatology, 117(1-2), 343-361.

OSİB, (2013), Havza koruma eylem planlarının hazırlanması projesi Doğu Karadeniz Havzası, Türkiye Bilimsel ve Teknolojik Araştırma Kurumu (TÜBİTAK) Marmara Araştırma Merkezi, Çevre ve Temiz Üretim Enstitüsü, Ankara.

Özfalcı Y., (2008), Çok değişkenli uyarlanabilir regresyon kesitleri: Mars, Yüksek Lisans Tezi, Gazi Üniversitesi, Fen Bilimleri Enstitüsü, Ankara.

SYGM, (2016), İklim Değişikliğinin Su Kaynaklarına Etkisi Projesi, Proje Nihai Raporu, Ek 24 - Doğu Karadeniz Havzası, T.C. Orman ve Su İşleri Bakanlığı, Su Yönetimi Genel Müdürlüğü, 135ss.

Toprak S., (2011), Çok değişkenli uyarlamalı regresyon eğrileri ve konik programlama ile zaman serilerinin modellenmesi, Yüksek Lisans Tezi, Dicle Üniversitesi, Fen Bilimleri Enstitüsü, Diyarbakır.

Tripathi S., Srinivas V.V., Nanjundiah R.S., (2006), Downscaling of precipitation for climate change scenarios: a support vector machine approach, Journal of Hydrology, 330(3-4), 621-640.

Ünal B., (2009), Çok değişkenli uyarlamalı regresyon uzanımları, Yüksek Lisans Tezi, Hacettepe Üniversitesi, Fen Bilimleri Enstitüsü, Ankara.

Vu M.T., Aribarg T., Supratid S., Raghavan S.V., Liong S.Y., (2016), Statistical downscaling rainfall using artificial neural network: significantly wetter Bangkok?, Theoretical and Applied Climatology, 126(3-4), 453-467.

Wagesho N., Jain M.K., Goel N.K., (2012), Effect of climate change on runoff generation: Application to Rift Valley Lakes basin of Ethiopia, Journal of Hydrologic Engineering, 18(8), 1048-1063.

Wilby R.L., Charles S.P., Zorita E., Timbal B., Whetton P., Mearns L.O., (2004), Guidelines for use of climate scenarios developed from statistical downscaling methods, https://www.ipcc-data.org/guidelines/dgm_no2_v1_09_2004.pdf, [Erişim 1 Mart 2020].

Wilby R.L., Harris I., (2006), A framework for assessing uncertainties in climate change impacts: low-flow scenarios for the River Thames, UK, Water Resources Research, 42(2), W02419, doi: doi.org/10.1029/2005WR004065.

Yüksek Ö., Kankal M., Üçüncü O., (2013), Assessment of big floods in the Eastern Black Sea Basin of Turkey, Environmental Monitoring and Assessment, 185(1), 797-814. 